\title{
Effect of calcineurin inhibitor on post-endoscopic retrograde cholangiopancreatography pancreatitis in patients with liver transplantation: a propensity- matched cohort study
}

Hyoung-Chul Oh ${ }^{1}$, Jeffrey J. Easler ${ }^{2}$, Ihab I. El Hajj ${ }^{2}$, James Watkins ${ }^{2}$, Evan L. Fogel ${ }^{2}$, Lee McHenry ${ }^{2}$, Stuart Sherman ${ }^{2}$, Hyun Kang ${ }^{3}$, and Glen A. Lehman ${ }^{2}$

${ }^{1}$ Division of Gastroenterology, Chung-Ang University College of Medicine, Seoul, Korea; ${ }^{2}$ Division of Gastroenterology and Hepatology, Indiana University School of Medicine, Indianapolis, IN, USA; ${ }^{3}$ Department of Anesthesiology and Pain Medicine, Chung-Ang University College of Medicine, Seoul, Korea

Received: December 28, 2019

Revised : January 1, 2020

Accepted: January 4, 2020

\section{Correspondence to}

Glen A. Lehman, M.D.

Division of Gastroenterology and Hepatology, Indiana University School of Medicine, 550 N. University Boulvard, Suite 1634, Indianapolis, IN 46202, USA

Tel: +1-317-944-0925

Fax: +1-317-968-1265

E-mail: glehman@iu.edu

https://orcid.org/0000-00034897-4077
Background/Aims: A calcineurin inhibitor may alter pancreatic function and inflammatory reaction. This study aimed to determine the possible pharmacologic effect of the calcineurin inhibitor, tacrolimus, on pancreatic function, and to determine its preventive effect on post-endoscopic retrograde cholangiopancreatography (ERCP) pancreatitis in liver transplantation (LT) patients.

Methods: The serum amylase and lipase values before and after LT were compared. The frequency of post-ERCP pancreatitis was compared between non-LT and LT patients, using propensity score matching method.

Results: Median serum amylase values (normal range, 19 to $86 \mathrm{U} / \mathrm{L}$ ) were $49.0 \mathrm{U} / \mathrm{L}$ (38.0 to 68.0) before LT and 27.0 U/L (19.3 to 36.8) after LT, and median serum lipase values (normal range, 7 to $59 \mathrm{U} / \mathrm{L}$ ) were $40.0 \mathrm{U} / \mathrm{L}$ (26.5 to 54.0 ) before LT and $10.5 \mathrm{U} / \mathrm{L}(6.0$ to 21.0$)$ after LT. Both serum amylase and lipase values significantly decreased after LT $(p<0.001)$, and to a level comparable to chronic pancreatitis. There was a marginal significant difference between the non-LT and LT groups before the propensity score matching with respect to frequency of post-ERCP pancreatitis $(16[3.2 \%]$ in non-LT group vs. 2 [0.9\%] in LT group, $p=0.069)$. After propensity score matching, a marginal significant difference still existed with respect to frequency of post-ERCP pancreatitis $(7$ [4.8\%] in non-LT group vs. 1 [0.7\%] in LT group, $p=0.067$ ).

Conclusions: The immunosuppression with calcineurin inhibitor may reduce not only the pancreatic enzyme dynamics but also inciting inflammatory event including post-ERCP pancreatitis.

Keywords: Cholangiopancreatography, endoscopic retrograde; Pancreatitis; Liver transplantation; Calcineurin inhibitos

\section{INTRODUCTION}

Post-endoscopic retrograde cholangiopancreatography (ERCP) pancreatitis (PEP) is the most common adverse event after ERCP. Its frequency ranges from $2 \%$ to $4 \%$ in low-risk patients to $8 \%$ to $20 \%$ in high-risk patients $[1,2]$. The causes of PEP are multi-factorial. Both patientand procedure-related factors induce various inciting 
events that may cause mechanical, hydrostatic, chemical and enzymatic injury. These inciting events ultimately lead to a common inflammatory cycle of inappropriate activation of pancreatic enzymes and auto-digestion [1].

Recently, rectal nonsteroidal anti-inflammatory drugs (NSAIDs) have been shown to be effective to decrease the frequency of PEP. The frequencies of PEP decreased to $1.5 \%$ to $3.0 \%$ in low-risk patients $[3,4]$ and $4.5 \%$ to $9.0 \%$ in high-risk patients [2-4] after the introduction of rectal NSAIDs. On the other hand, the frequency of PEP among the patients with liver transplantation (LT) has been reported to be $2.7 \%$ to $4.7 \%$ without rectal NSAIDs [5-8].

Overall, the frequency of PEP appears to be lower in patients with LT. The hypothetical mechanism might be that the immunosuppression after LT may attenuate the inflammatory response related with PEP and reduce the development of PEP in patients with LT.

Recent experimental studies demonstrated that protease activation in cerulein-induced pancreatitis is dependent on calcineurin activation and exposure to radiopaque contrast agents induced pancreatitis in a mouse model via activation of calcineurin. In addition, calcineurin-deficient mice had reduced histologic severity of pancreatitis and the calcineurin inhibitor, tacrolimus (FK506), reduced pathologic protease activation and pancreatitis $[9,10]$. Therefore, it might be assumed that calcineurin inhibitor has a preventive role in post-ERCP pancreatitis. This study aimed (1) to determine the pharmacologic effect of calcineurin inhibitor on pancreatic enzyme dynamics by comparing the serum amylase and lipase value before and after immunosuppression in LT patients, and (2) to determine the preventive effect of calcineurin inhibitor on post-ERCP pancreatitis in LT patients by comparing with non-LT patients.

\section{METHODS}

This retrospective study was approved by Institutional Review Board at Indiana University (1609379618). The informed consents were waived because the retrospective nature of this study.

\section{Patients}

From Jul 2012 to May 2016, 218 consecutive LT patients with duct-to-duct anastomosis who underwent ERCP due to post-LT suspected biliary complications for the first time were included in the LT group. From Nov 2015 to May 2016, 495 consecutive patients who underwent ERCP for the first time were enrolled into non-LT group. ERCP procedures were performed by seven experienced endoscopists. For prevention of PEP, prophylactic rectal indomethacin and/or pancreatic stent were provided based on the individual endoscopist's discretion. Medical records were reviewed one-by-one and demographics, serum amylase and lipase values before and after LT, procedure details related with PEP including pancreatic stent placement and pancreatic duct (PD) opacification, provision of rectal indomethacin, immunosuppressants taken at the time of ERCP in LT group, and occurrence of PEP were collected. As this study was conducted as a retrospective analysis, the risk or preventive factors related with post-ERCP pancreatitis that could be determined by the review of ERCP reports were selected: PD stent placement [11,12], PD opacification [13], and use of rectal indomethacin [2].

For comparison of serum amylase and lipase before and after LT, 96 LT patients who had serum amylase (n = 96) and/or lipase $(n=53)$ values before and after LT were identified among $218 \mathrm{LT}$ patients. The serum amylase and lipase were drawn at the discretion of their liver transplant managing physicians. If multiple amylase and lipase values were present, the lowest ones were used for analysis. The serum amylase and lipase values before and after LT were compared with those from the patients with non-calcific chronic pancreatitis (NCCP) and calcific chronic pancreatitis (CCP) enrolled in our previous studies $[14,15]$.

\section{Outcomes}

The primary outcomes in this retrospective study were (1) the frequency of PEP between LT and non-LT group, and (2) the comparison of serum pancreatic enzyme values before and after LT.

\section{Immunosuppression after LT}

The standard immunosuppression protocol at Indiana University Hospital includes anti-thymocyte globulin and tacrolimus (FK506). Anti-thymocyte globulin (1.5 $\mathrm{mg} / \mathrm{kg}$ of actual body weight) is given intravenously on post-operative day (POD) 1, 3, and 5. Methylprednisolone 
is given on $\mathrm{POD} 1$ (250 $\mathrm{mg}$ ) and $\mathrm{POD}_{3}(125 \mathrm{mg})$ and prednisone (20 mg) is given on POD 5. Rituximab $\left(150 \mathrm{mg} / \mathrm{m}^{2}\right.$ of body surface) is given on POD 2. All patients begin to receive oral tacrolimus on day 2 ( $2 \mathrm{mg}$ twice daily) and the dosage is adjusted to maintain serum trough concentration of $8 \mathrm{ng} / \mathrm{mL}$ by POD 7 through 3 months and $6 \mathrm{ng} / \mathrm{mL}$ thereafter.

\section{Definition}

PD opacification was defined as occurring when the contrast was injected and opacified any portion of the PD. Post-ERCP pancreatitis was diagnosed when new-onset or increased abdominal pain caused a hospital admission or prolonged hospital stay and was associated with an increase in amylase or lipase levels of at least 3-fold above normal 24 hours after the procedure [16]. Pancreatitis severity was graded as mild for patients with up to 3 additional hospital days and moderate for those staying between 4 and 10 days. Pancreatitis was graded as severe in patients who spent more than 10 days in the hospital or if any of the following occurred: hemorrhagic pancreatitis, pancreatic necrosis, development of a pancreatic pseudocyst, or the need for percutaneous drainage or surgery [16].

\section{Statistical analysis}

Because this was a retrospective cohort study, patients were not randomized before the interventions. Therefore, we used a propensity score matching method to reduce the bias due to confounding [17]. A logistic regression model was created to calculate the propensity score. Patients in each group were matched and allocated according to a propensity score, which reflected their possibility of undergoing LT. The following variables were tested to determine the propensity score: age, sex, use of PD stent, rectal indomethacin, PD opacification [18].

The patients in each group were matched in a 1:1 ratio using a propensity score matching method. A patient in group LT was matched with one in group non-LT based on the similarity of their propensity scores. Patients whose caliper radius was over 0.001 at the nearest available matching were excluded from this study.

The standardized differences for covariates were tested to estimate the relevance of balance between the matched groups. Standardized difference is the difference in means between both groups in units of standard deviation. If the standardized difference between both groups was $<20 \%$, their comparability was considered to be good [19].

For continuous variables, data distribution was first evaluated for normality using the Shapiro-Wilk test. Normally distributed data were then compared using parametric methods while non-normally distributed data were analyzed using non-parametric methods. Before the matching, an unpaired $t$ test or Mann-Whitney $U$ test was used to compare the continuous variables, and the chi-square test or Fisher's exact test was used to compare the descriptive variables.

After the matching, statistical differences between non-LT and LT groups were evaluated using the paired $t$, the Wilcoxon signed-rank, or the McNemar test. The continuous variables were expressed as the mean \pm standard deviation and the descriptive variables were expressed as absolute numbers (\%).

p values $<0.05$ were considered statistically significant. All the analyses were conducted using the SPSS software suite version 23 (IBM Corp., Armonk, NY, USA).

\section{RESULTS}

\section{Change in serum amylase and lipase values after immunosuppression}

Mean and median serum amylase and lipase values are summarized in Table 1. Median serum amylase values (normal range, 19 to $86 \mathrm{U} / \mathrm{L}$ ) were $49.0 \mathrm{U} / \mathrm{L}$ (38.0 to 68.0) before LT and 27.0 U/L (19.3 to 36.8) after LT, and significantly decreased after LT (immunosuppression) $(p<$ o.001). On the other hand, when the median serum amylase value after LT was compared with the median values among NCCP (34.0 U/L; interquartile range [IQR], 24.5 to 49.0) and CCP (31.7 U/L, IQR, 20.0 to 40.8), the median serum amylase value after LT decreased to a level lower than NCCP $(p<0.05)$ or comparable to CCP $(p=0.793)$.

The median serum lipase value (normal range, 7 to 59 $\mathrm{U} / \mathrm{L}$ ) was $40.0 \mathrm{U} / \mathrm{L}$ (26.5 to 54.0) before LT and 10.5 U/L (6.0 to 21.0) after LT, and significantly decreased after LT (immunosuppression) $(p<0.001)$. Similar to the results with amylase, when the median serum lipase value after LT was compared with the median value among NCCP (22.3 U/L; IQR, 9.0 to 30.0) and CCP patients (10.0 U/L; IQR, 3.0 to 19.0), the median serum lipase value after LT 
Table 1. Comparison of serum amylase and lipase among before transplantation, after transplantation, NCCP, and CCP

\begin{tabular}{|c|c|c|c|c|c|c|c|c|}
\hline \multirow[b]{2}{*}{ Variable } & \multicolumn{4}{|c|}{ Serum amylase } & \multicolumn{4}{|c|}{ Serum lipase } \\
\hline & $\begin{array}{l}\text { Before LT } \\
(n=96)\end{array}$ & $\begin{array}{l}\text { After LT } \\
(n=96)\end{array}$ & $\begin{array}{l}\text { NCCP } \\
(\mathrm{n}=99)\end{array}$ & $\begin{array}{c}\text { CCP } \\
(n=112) \\
\end{array}$ & $\begin{array}{l}\text { Before LT } \\
(\mathrm{n}=53)\end{array}$ & $\begin{array}{l}\text { After LT } \\
(\mathrm{n}=96)\end{array}$ & $\begin{array}{l}\text { NCCP } \\
(\mathrm{n}=99)\end{array}$ & $\begin{array}{c}\text { CCP } \\
(n=112)\end{array}$ \\
\hline Mean & 53.04 & 29.49 & 36.99 & 31.66 & 42.43 & 15.15 & 22.30 & 12.83 \\
\hline Median & 49.00 & $27.00^{\mathrm{a}}$ & $34.00^{\mathrm{a}, \mathrm{b}}$ & $30.00^{\mathrm{a}}$ & 40.00 & $10.50^{c}$ & $19.00^{c, d}$ & $10.00^{c}$ \\
\hline $\mathrm{SD}$ & 19.604 & 14.609 & $17 \cdot 374$ & 15.835 & 20.936 & 13.145 & 15.799 & 11.472 \\
\hline Range & $21-98$ & $1-74$ & $1-85$ & $10-79$ & $8-123$ & $3-65$ & $3-74$ & $2-58$ \\
\hline IQR & $38.00-68.00$ & $19.25-36.75$ & $24.50-49.00$ & $20.00-40.75$ & $26.50-54.00$ & $6.00-21.00$ & $9.00-30.00$ & $3.00-19.00$ \\
\hline
\end{tabular}

NCCP, non-calcific chronic pancreatitis; CCP, calcific chronic pancreatitis; LT, liver transplantation; SD, standard deviation; IQR, interquartile range.

${ }^{a}$ Before LT vs. After LT, before LT vs. NCCP, before LT vs. CCP, $p<0.001$.

${ }^{b}$ After LT vs. NCCP, $p<0.05$.

${ }^{\mathrm{c}}$ Before LT vs. After LT, before LT vs. NCCP, before LT vs. CCP, $p<0.001$.

${ }^{\mathrm{d}}$ After LT vs. NCCP, $p<0.05$.
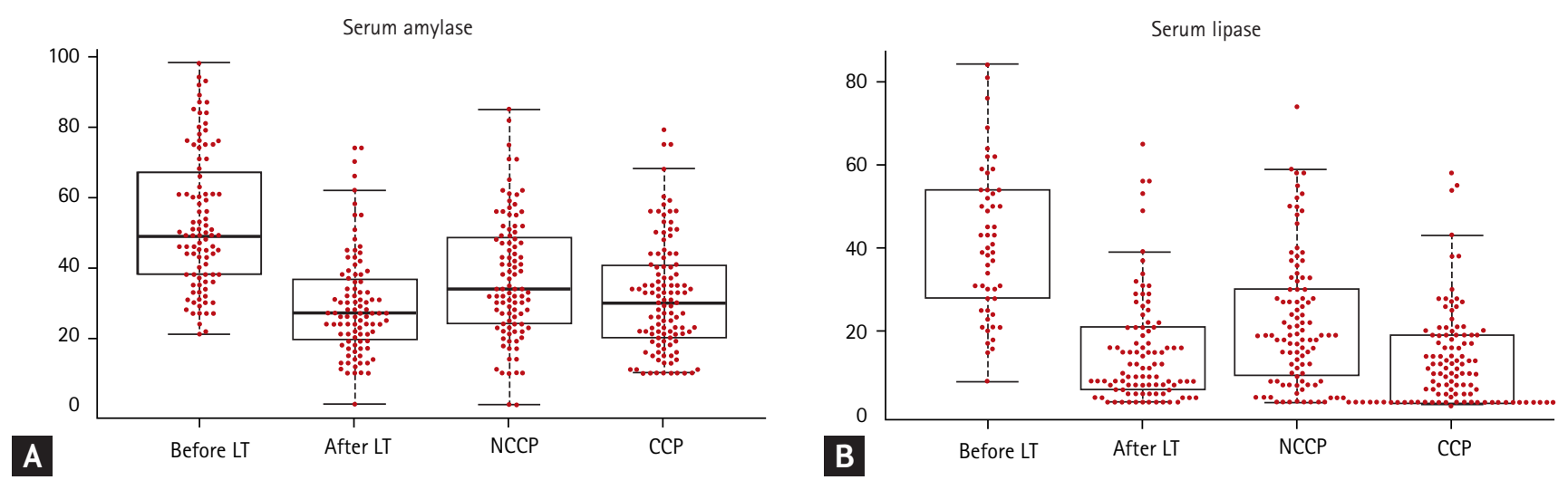

Figure 1. (A) Serum amylase and (B) lipase values among the four groups: before liver transplantation (LT), after liver transplantation, non-calcific chronic pancreatitis (NCCP), and calcific chronic pancreatitis (CCP).

decreased to a level lower than NCCP $(p<0.05)$ or comparable to $\operatorname{CCP}(p=0.676)$. Therefore, serum amylase and lipase values after LT (immunosuppression) decreased to a level of chronic calcific pancreatitis. Fig. 1 shows the distribution of serum amylase and lipase values among the four groups.

\section{Frequency of post-ERCP pancreatitis before and after propensity score matching}

We reviewed the records of 713 patients. The number of patients who underwent LT and did not undergo LT was 218 and 495, respectively. The characteristics of patients are shown in Table 2.
Four of the five confounding variables (sex, PD stent, rectal indomethacin, and PD opacification) showed statistical difference and three of the five confounding variables showed poor standardized difference scores before propensity score matching, i.e., the following confounding variables differed significantly between non-LT group and LT group: sex, placement of PD stent, administration of rectal indomethacin and PD opacification (Table 2).

We generated 146 matched pairs using the propensity score matching. After propensity score matching, there were 408 patients in non-LT group and 115 in LT group. All five confounding variables had an acceptable 
Table 2. Patient characteristics in total and matched cohorts

\begin{tabular}{|c|c|c|c|c|c|c|c|c|}
\hline \multirow[b]{2}{*}{ Characteristic } & \multicolumn{4}{|c|}{ Total set } & \multicolumn{4}{|c|}{ Matched set } \\
\hline & $\begin{array}{c}\text { Non-LT patients } \\
(\mathrm{n}=495)\end{array}$ & $\begin{array}{l}\text { LT patients } \\
(\mathrm{n}=218)\end{array}$ & $\mathrm{SD}, \%$ & $p$ value & $\begin{array}{l}\text { Non-LT patients } \\
(\mathrm{n}=146)\end{array}$ & $\begin{array}{l}\text { LT patients } \\
(\mathrm{n}=146)\end{array}$ & $\mathrm{SD}, \%$ & $p$ value \\
\hline Age, yr & $\begin{array}{c}55.1 \pm 20.6 \\
(3-96)\end{array}$ & $\begin{array}{c}54.2 \pm 12.2 \\
(3-75)\end{array}$ & $4 \cdot 9$ & 0.519 & $\begin{array}{c}56.3 \pm 20.4 \\
(3-96)\end{array}$ & $\begin{array}{c}55 \cdot 3 \pm 11.8 \\
(3-75)\end{array}$ & 6.0 & 0.594 \\
\hline Sex, male:female & $195: 300$ & $144: 74$ & 50.9 & $<0.001^{\mathrm{a}}$ & $92: 54$ & $87: 59$ & $5 \cdot 54$ & 0.548 \\
\hline PD stent & $155(31.3)$ & $25(11.5)$ & 92.5 & $<0.001^{\mathrm{a}}$ & $24(16.4)$ & $21(14 \cdot 4)$ & 12.1 & 0.627 \\
\hline Rectal indomethacin & $287(58.0)$ & $54(24.8)$ & 80.2 & $<0.001^{\mathrm{a}}$ & $41(28.1)$ & $39(26.7)$ & 4.98 & 0.793 \\
\hline PD opacification & $275(55 \cdot 6)$ & $104(47 \cdot 7)$ & $15 \cdot 3$ & $<0.001^{\mathrm{a}}$ & $70(47.9)$ & $69(47 \cdot 3)$ & 1.25 & 0.907 \\
\hline Post-ERCP pancreatitis & $16(3.2)$ & $2(0.9)$ & & 0.069 & $7(4.8)$ & $1(0.7)$ & & 0.067 \\
\hline Mild/Mod/Severe & $14 / 1 / 1$ & $1 / 1 / 0$ & & 0.178 & $5 / 1 / 1$ & 1/0/0 & & 0.188 \\
\hline
\end{tabular}

Values are expressed as mean \pm SD (range) or number (\%).

LT, liver transplantation; SD, standard deviation; PD, pancreatic duct; ERCP, endoscopic retrograde cholangiopancreatography. ${ }^{a} p<0.05$ between groups.

standardized difference (i.e., $<20 \%$ ), indicating that the matching procedure was efficient in creating a balance between the non-LT and LT groups (Table 2).

There was marginal significant difference between both non-LT and LT groups before the propensity score matching with respect to frequency of post-ERCP pancreatitis ( 16 [3.2\%] in non-LT group vs. 2 [0.9\%] in LT group, $p=0.069$ ). After propensity score matching, marginal significant difference still existed with respect to frequency of post-ERCP pancreatitis (7 [4.8\%] in non-LT group vs. $1[0.7 \%]$ in LT group, $p=0.067)$.

\section{DISCUSSION}

The current study showed that the serum amylase and lipase values significantly decreased after immunosuppression with the calcineurin inhibitor (Tacrolimus) among the patients with LT, to a level comparable to patients with chronic pancreatitis. This finding strongly suggests that a calcineurin inhibitor reduces pancreatic function via calcinerin inhibition in humans, as protease inhibition via calcineurin inhibition shown in the experimental pancreatitis model $[9,10]$.

Considering the average-to-high risk of post-ERCP pancreatitis in non-LT group, the overall frequency of post-ERCP pancreatitis in non-LT group was as low as $3.2 \%(n=16)$, which was much lower than previously reported (ranging from $7.2 \%$ to $9.0 \%$ ) $[2,20]$. Such low frequency in the current study might be due to the frequent use of rectal indomethacin (58\%) and PD stents (31\%). These two potent preventers probably contributed to only the marginal difference in the frequency of post-ERCP pancreatitis between non-LT and LT groups.

One previous report in 2009 before the use of rectal indomethacin was widely adopted in clinical practice showed that the frequency of post-ERCP pancreatitis was significantly lower in LT group than non-LT group (4.7\% vs. 9.6\%, $p=0.04$ ) [8].

A report from Mayo Clinic showed that the use of steroids after LT was associated with lower frequency of post-ERCP pancreatitis. The immunosuppression regimens at Mayo Clinic included a long-term (4-month period) use of corticosteroid after LT. This strategy might alter the inflammatory response to inciting events including post-ERCP pancreatitis [6]. In contrast, the immunosuppression strategy at Indiana University includes a short-term use of corticosteroid and early use of the calcineurin inhibitor (Tacrolimus). Short term one or two doses of oral corticosteroids have mostly been shown to be ineffective in reducing post-ERCP pancreatitis [21,22].

Could the calcineurin inhibitor (Tacrolimus) be a candidate drug for the prevention of post-ERCP pancreatitis? The majority of patients in the LT group received calcineurin inhibitor for at least 3 days before ERCP and a level of drug concentration that may be effective for the prevention of post-ERCP was probably achieved at 
the time of ERCP since the steady-state of calcineurin inhibitor is achieved within 5 days [23]. Since many patients undergo ERCP on an emergent basis, whether a single or double dose of the calcineurin inhibitor before ERCP could be effective for post-ERCP pancreatitis prevention will require prospective study.

Indomethacin at a single dose of 10omg per rectum has been shown to decrease the rate of post-ERCP pancreatitis [2]. A second large prospective study showed that $200 \mathrm{mg}$ indomethacin was not superior to 100mg. This suggests that maximal dosing (at least of indomethacin) is not needed for post-ERCP pancreatitis prevention [24].

In the current study, authors used a propensity score matching method to reduce the bias due to confounding factors including placement of PD stent, administration of rectal indomethacin, and PD opacification. However, a large-scaled prospective study will be needed to determine the effect of calcineurin inhibitors on pancreatic function and prophylaxis of post-ERCP pancreatitis.

In conclusion, the immunosuppression with calcineurin inhibitor may reduce not only pancreatic enzyme dynamics but also inciting inflammatory events including post-ERCP pancreatitis.

\section{KEY MESSAGE}

1. Serum amylase and lipase values significantly decreased after immunosuppression with the calcineurin inhibitor among the patients with liver transplantation (LT).

2. There was marginal significant difference between both non-LT and LT groups after the propensity score matching with respect to frequency of post-endoscopic retrograde cholangiopancreatography pancreatitis.

\section{Conflict of interest}

No potential conflict of interest relevant to this article was reported.

\section{REFERENCES}

1. Freeman ML, Guda NM. Prevention of post-ERCP pan- creatitis: a comprehensive review. Gastrointest Endosc 2004;59:845-864.

2. Elmunzer BJ, Scheiman JM, Lehman GA, et al. A randomized trial of rectal indomethacin to prevent post-ERCP pancreatitis. N Engl J Med 2012;366:1414-1422.

3. Thiruvengadam NR, Forde KA, Ma GK, et al. Rectal indomethacin reduces pancreatitis in high- and low-risk patients undergoing endoscopic retrograde cholangiopancreatography. Gastroenterology 2016;151:288-297.

4. Luo H, Zhao L, Leung J, et al. Routine pre-procedural rectal indometacin versus selective post-procedural rectal indometacin to prevent pancreatitis in patients undergoing endoscopic retrograde cholangiopancreatography: a multicentre, single-blinded, randomised controlled trial. Lancet 2016;387:2293-2301.

5. Balderramo D, Bordas JM, Sendino O, et al. Complications after ERCP in liver transplant recipients. Gastrointest Endosc 2011;74:285-294.

6. Law R, Leal C, Dayyeh BA, et al. Role of immunosuppression in post-endoscopic retrograde cholangiopancreatography pancreatitis after liver transplantation: a retrospective analysis. Liver Transpl 2013;19:1354-1360.

7. Ambrus RB, Svendsen LB, Hillingso JG, Hansen ML, Achiam MP. Post-endoscopic retrograde cholangiopancreaticography complications in liver transplanted patients, a single-center experience. Scand J Surg 2015;104:86-91.

8. Sanna C, Saracco GM, Reggio D, et al. Endoscopic retrograde cholangiopancreatography in patients with biliary complications after orthotopic liver transplantation: outcomes and complications. Transplant Proc 2009;41:13191321.

9. Shah AU, Sarwar A, Orabi AI, et al. Protease activation during in vivo pancreatitis is dependent on calcineurin activation. Am J Physiol Gastrointest Liver Physiol 2009;297:G967-G973.

10. Jin S, Orabi AI, Le T, et al. Exposure to radioc ontrast agents induces pancreatic inflammation by activation of nuclear factor- $\mathrm{\kappa} \mathrm{B}$, calcium signaling, and calcineurin. Gastroenterology 2015;149:753-764.

11. Sofuni A, Maguchi H, Itoi T, et al. Prophylaxis of post-endoscopic retrograde cholangiopancreatography pancreatitis by an endoscopic pancreatic spontaneous dislodgement stent. Clin Gastroenterol Hepatol 2007;5:1339-1346.

12. Mazaki T, Mado K, Masuda H, Shiono M. Prophylactic pancreatic stent placement and post-ERCP pancreatitis: an updated meta-analysis. J Gastroenterol 2014;49:343-355. 
13. Cheon YK, Cho KB, Watkins JL, et al. Frequency and severity of post-ERCP pancreatitis correlated with extent of pancreatic ductal opacification. Gastrointest Endosc 2007;65:385-393.

14. Kwon CI, Kim HJ, Korc P, et al. Can we detect chronic pancreatitis with low serum pancreatic enzyme levels? Pancreas 2016;45:1184-1188.

15. Oh HC, Kwon CI, El Hajj II, et al. Low serum pancreatic amylase and lipase values are simple and useful predictors to diagnose chronic pancreatitis. Gut Liver 2017;11:878-883.

16. Cotton PB, Lehman G, Vennes J, et al. Endoscopic sphincterotomy complications and their management: an attempt at consensus. Gastrointest Endosc 1991;37:383-393.

17. Perkins SM, Tu W, Underhill MG, Zhou XH, Murray MD. The use of propensity scores in pharmacoepidemiologic research. Pharmacoepidemiol Drug Saf 2000;9:93-101.

18. Brookhart MA, Schneeweiss S, Rothman KJ, Glynn RJ, Avorn J, Sturmer T. Variable selection for propensity score models. Am J Epidemiol 2006;163:1149-1156.

19. Austin PC. A critical appraisal of propensity-score matching in the medical literature between 1996 and 2003. Stat
Med 2008;27:2037-2049.

20. Levenick JM, Gordon SR, Fadden LL, et al. Rectal indomethacin does not prevent post-ERCP pancreatitis in consecutive patients. Gastroenterology 2016;150:911-917.

21. Sherman S, Blaut U, Watkins JL, et al. Does prophylactic administration of corticosteroid reduce the risk and severity of post-ERCP pancreatitis: a randomized, prospective, multicenter study. Gastrointest Endosc 2003;58:23-29.

22. Manolakopoulos S, Avgerinos A, Vlachogiannakos J, et al. Octreotide versus hydrocortisone versus placebo in the prevention of post-ERCP pancreatitis: a multicenter randomized controlled trial. Gastrointest Endosc 2002;55:470475 .

23. Tanzi MG, Undre N, Keirns J, Fitzsimmons WE, Brown M, First MR. Pharmacokinetics of prolonged-release tacrolimus and implications for use in solid organ transplant recipients. Clin Transplant 2016;30:901-911.

24. Fogel EL, Lehman GA, Tarnasky P, et al. Rectal indomethacin dose escalation for prevention of post-ERCP pancreatitis in high-risk patients: preliminary report of a multicenter randomized trial (RIDE Trial): Category Award (Biliary/Pancreas) 1. Am J Gastroenterol 2018;113:S1. 